\title{
8. Families from a network perspective
}

\author{
Gil Viry and Andreas Herz
}

\section{INTRODUCTION: NETWORK APPROACH IN FAMILY RESEARCH}

This chapter is concerned with the network approach (or network perspective) to families. Rather than analysing specific dyads (e.g., parent-child bond), the network approach emphasises that the form and quality of family and intimate relationships - such as the degree of care, support, or conflict they provide - should be related to the larger set of personal relationships; i.e., networks. For example, research on North American families has shown that parents and children are more likely to be supportive in densely-knit family networks with a high proportion of parents and children, because these networks enforce norms of supportiveness and facilitate the coordination of support (Wellman and Frank 2001).

The network approach has been successfully used in the field of family research at least since the seminal work of Elisabeth Bott (1957), and has become more prominent since the 1980s (e.g., Acock and Hurlbert 1990; Johnson and Leslie 1982; Milardo 1988; Wellman and Wortley 1989). We can identify two main strands of the network approach in the literature: the structural and the dyadic approach. The first approach has mainly been used to analyse families at the network level by aggregating information about individual family members and family relationships into meaningful network indices, such as density (degree of interconnection among network members) or homogeneity (their variability in some key characteristics, for example, the proportion of kin) (Milardo 1988; Widmer 2016). This research has been particularly insightful in revealing the diversity and significance of family structures beyond the nuclear family and particular dyads. By contrast, the second strand, which is most prominent in the field of social support, has focused on specific family dyads, especially on marital and parent-child relationships, and more rarely on other types of relationships, such as siblings (Cicirelli 2013) and grandparents (Mueller et al. 2002; Silverstein and Marenco, 2001). Drawing on recent developments in quantitative social network analysis (SNA) (Lazega and Snijders 2015; Vacca 2018; van Duijn et al. 1999; Wellman and Frank 2001), this chapter presents a multilevel analysis of personal networks as a powerful approach to studying family and intimate relationships by simultaneously integrating analysis at the individual, dyadic (tie), and network levels. These developments offer promising ways to combine the strengths of both strands, to extend the scope of family research, and to strengthen the importance of the network approach as an indispensable framework for understanding issues of interest to family studies.

We begin by briefly presenting the key principles of the network approach to families, and provide an overview of the main ways scholars can use SNA to design research and analyse family structures. To illustrate recent developments in the multilevel analysis of personal networks, we use data on the ego-centric family networks of 666 adults living in Switzerland. We conclude by critically discussing some pitfalls of this approach, and by suggesting some avenues for future research. 


\section{KEY PRINCIPLES OF THE NETWORK APPROACH AND ITS RELEVANCE FOR THE STUDY OF FAMILIES}

In this section, we provide a brief overview of the network approach, and discuss the relevance of this framework for conceptualising and analysing families. ${ }^{1}$ The network approach encompasses the theoretical views and method(olog)ical considerations of SNA, which revolve around what Wellman (1988) termed 'structural analysis'. A social network is formally defined as a specific set of linkages among a defined set of social actors (Mitchell 1969). The core idea of the network approach is that patterns of social relationships - i.e., the size, structure, composition, or geography of social networks - can be used to understand and explain social phenomena, and how social relationships and networks work.

Sociological explanations often seek to explain human behaviour and social phenomena based on the categorical attributes of actors, such as their age, class, gender, and ethnicity. By contrast, the network approach takes direct and indirect social connections as the fundamental unit of analysis, and aims to shed light on the structure and patterns of the interconnections between actors, based on the assumption that this structure matters. Emirbayer and Goodwin (1994, p. 1414) called this the 'anticategorical imperative'. Individual or social attributes are not dismissed, but are framed in relation to different patterns of social relationships. Thus, the ontological position of the network perspective places a strong emphasis on social relationships and the patterns they form. For example, new parents will differ from non-parents not only because of their new parent-child relationships and the new roles these relationships entail, but because they are embedded in a whole set of interrelated relationships that differ in their form and quality. For example, compared with non-parents, parents may become more involved with their parents-in-law or have a higher proportion of friends who also have children. This approach assumes that families are not reducible to the properties of separate relationships (or dyads), but should instead be analysed as network patterns; i.e., as configurations that involve more than two actors. For instance, the quality of the parent-child bond should not be examined in isolation, but rather as embedded in a larger set of family and intimate relationships that include siblings, grandparents, godparents, neighbours, and other people who play important roles in the lives of the parent and the child.

Another key principle of the network approach is that it focuses on meaningful relationships between actors, rather than on formal relationships based on institutional definitions or common attributes, such as living in the same household or being related by birth, marriage, or adoption. This principle aligns with some contemporary family approaches associated with intimacy and personal life (Jamieson 1998; Smart 2007), which emphasise the plurality of family forms and practices of intimacy. These approaches aim to go beyond the conventional assumption that a family consists of a heterosexual couple in a romantic relationship living together with their children (Budgeon and Roseneil 2004) to explore the more fluid character of intimate relationships, which may, for example, include close friends and sexual partners. Because the network approach to families also focuses on what is passing through social relationships, it overlaps and has some affinity with perspectives that emphasise 'displaying' (Finch 2007) and 'doing' families through a set of practices, such as sharing, loving, confiding, arguing, and caring for others (Morgan 2011). Because it does not a priori assume a fixed definition of what constitutes a family, the network approach can contribute to this broader understanding of family life. It can also add to theoretical and methodological debates about locating its contours by studying the patterns of social and intimate relationships that matter 
to people in providing affection, care, support, companionship, sense of belonging, and connectedness. Breaking the traditional boundaries of public/private, given/chosen, kin/non-kin, or close/superficial relationships, this approach allows family researchers to apply a greater degree of complexity in mapping and analysing which relationships matter to people; how, when, where, and why these relationships matter; and what the consequences of these relationships are. It is, however, essential that researchers make explicit the theoretical assumptions underpinning notions of what constitutes a meaningful relationship. As Crossley (2010) puts it, the patterns of connections never exist independently of the specific content of the interactions, which generate and sustain the relationships that constitute a network. Whatever the degree of standardisation employed by the researchers using quantitative or qualitative SNA, identifying all possible relationships within families requires explicit criteria for the study of these relationships. While some researchers reduce the family to a set of relationships of a particular quality (e.g., degree of intimacy) (Lenz 2009; Lenz and Nestmann 2009), or subsume the family under the concept of personal communities of socially close ties (Pahl and Spencer 2010; Wellman et al. 1988), other researchers use a more subjective definition of the family by asking people to identify their meaningful family members (Widmer 1999, 2016). What all of these network studies have in common is that they focus on the patterning of relationships in seeking to understand family life.

While a central assumption of the network approach is that actions are embedded in social relationships (Granovetter 1985), more recent debates have placed special emphasis on the actors' agency. Criticising the insufficient attention given to the way in which networks are constructed and lived by actors who reflexively operate within them, relational sociology has sought to overcome the dichotomies (such as agency-structure or micro-macro) used by traditional sociological approaches (Emirbayer and Goodwin 1994; Emirbayer and Mische 1998). In contrast to strongly structural and deterministic approaches, this research has stressed the interplay between dynamic social networks and individual actions. While social networks shape the attitudes, decisions, and resources of individual actors; these individuals are, in turn, also agents in the formation and transformation of social networks over time in response to past, present, and imagined future situations. According to these authors, the network approach must pay attention to the subjective meanings (and, thus, to culture) that actors attach to social relationships, stressing the mutual influence of network structures and cultural elements, such as norms, conventions, identities, values, and beliefs. In the field of family research, this involves investigating how people and cultures demarcate family relationships from other types of relationships, such as business or friendship ties. It also involves recognising that family relationships are sedimented and ongoing histories of interaction that shape their meanings and how actors engage with these relationships. In the conceptualisation of agency as a phenomenon to be studied in relationships, there is growing interest in examining how individuals and families engage in network building; and how social networks change, not only in response to life circumstances, but also through the characteristics and purposive actions of culturally embedded individuals.

In SNA, family networks are conceptualised both as (a) predictors and as (b) outcomes depending on the research question addressed. (a) An important area of research has analysed how social networks provide resources (e.g., support) and enforce social norms that may affect individual behaviours and well-being, such as when handling stress, conjugal instability, or parenthood (see, e.g., Bost et al. 2002; Felmlee 2001). Bott's (1957) seminal studies initiated this body of research by showing that the degree of segregation in marital roles varies with the 
density of family networks. Studying 20 families in London, she found that closely knit networks provided high levels of mutual assistance and exercised considerable social control over the couples, who tended to adopt traditional family norms and a gendered division of labour between the husband and the wife. These results have recently been confirmed by Giudici and Widmer (2017) using Swiss longitudinal data. (b) In the conceptualisation of networks as outcomes, studies often look at how network characteristics vary across social categories and family forms (widowers, stepfamilies, etc.). The body of research that examines how personal and family networks change in response to major family life events falls into this realm (e.g., Antonucci et al. 2011; Bidart and Lavenu 2005; Kalmijn 2003; Voorpostel 2013), like research that studies how migrants and spatially mobile individuals sustain transnational and multilocal families (Hein et al. 2019; Herz 2015; Lubbers et al. 2010; Molina et al. 2015; Ryan 2011; Viry 2012; Viry et al. 2017).

\section{DESIGNING AND ANALYSING FAMILY STRUCTURES THROUGH SOCIAL NETWORK ANALYSIS}

SNA studies use different designs that are derived from past developments. While it is beyond the scope of this chapter to present the early developments that led to these designs, it is important to acknowledge the strong qualitative roots of SNA in social anthropology, social psychology, and sociology (see, e.g., Prell 2012 or Scott 2017 for a brief history). The landmark study by Elizabeth Bott (1957) is an example of a qualitative SNA in the realm of family, which is now seen as a source for methodological reflections on qualitative network analysis (Jones 2018). Since the 1980s, most SNA methods have been oriented towards 'standardised' designs that analyse social relationships and social structures by quantification, modelling, and visualisations of relational data. Recently, however, mixed-methods and qualitative approaches have been applied more frequently in an effort to better understand the meanings and history of relationships and networks, as well as the mechanisms and dynamics at play (Bellotti 2014; Crossley 2010; Herz et al. 2015; Hollstein, 2011). The recent development in qualitative and mixed-method designs in SNA has been particularly important in research on contemporary families in a transnational context (e.g., Bernardi 2011; Ryan 2011). In the rest of this chapter, we will focus on quantitative SNA methods because of their degree of systematicity. However, some aspects of the SNA research designs and methodological approaches can be applied to qualitative network research.

In quantitative SNA, two main designs can be distinguished. (1) 'Socio-centric' networks, also called 'complete' or 'whole' networks, consist of ties (or edges) between a defined set of actors (nodes), such as friendship ties among all of the employees of a given organisation. In socio-centric network designs, relationships are studied between actors in the given population. (2) 'Ego-centric' or personal networks involve ties defined from the perspective of a certain actor (ego) who is connected to other actors (alters) in his/her social environment, and the relationships between these alters. An ego-centric network design can also be used to investigate the friendship ties of the employees of an organisation. Unlike in socio-centric networks, in ego-centric networks, research participants can identify not only their relationships to actors from the set of actors studied (usually members of the organisation), but their relationships to actors outside this context (e.g., friends from other organisations) (Herz 2012). Because ego-centric network designs allow researchers to capture social structures from indi- 
vidual respondents, they can be incorporated fairly easily into survey questionnaires to gather information on relationships in families. Thus, ego-centric network designs have a strong advantage over socio-centric designs, in which it is usually necessary to interview all of the actors in the given system.

We can also differentiate network designs depending on whether they are based on relationship information that is collected 'only' for the (potential) direct relationships of the respondents, or whether they rely on so-called cognitive social structures (CSS), in which respondents provide information not only about their direct relationships, but about all possible relationships in a system (Krackhardt 1987). For example, a 'research participant A' not only provides information about whom s/he is connected to (e.g., B and C), but also about the existing relationships between all others (e.g., between B and C), even though s/he does not have a relationship with them. While this approach was developed using a socio-centric approach, it was translated to ego-centric networks in family research (Widmer 1999). This type of data should be seen as cognitive rather than behavioural, because evidence has shown that participants' descriptions of their own relationships and the relationships of others differ markedly from observations of these relationships (e.g., Bernard et al. 1979). However, the assumption of CSS methods is that perceptions of relationships do matter (Krackhardt 1987).

Because family research mainly uses ego-centric designs, we concentrate our discussion on the methods of data collection and analysis that employ this approach. ${ }^{2}$ For illustration purposes, we use data on the ego-centric family networks of 666 adults living in Switzerland obtained from the 2013 MosaiCH-ISSP survey using a nationally representative sample. In this survey, participants (egos) were asked about their significant family relationships (alters) and social support. ${ }^{3}$

\subsection{Data Collection}

SNA uses a wide range of data collection methods (e.g., direct observation, contact diaries, archives, document analysis). When collecting ego-centric network data through survey questionnaires, three steps are performed (Marsden 2011). In step 1, respondents (egos) are asked, via one or more 'name generator' items, to list the reference persons (alters) with whom they have relationships according to one or more criteria (e.g., lending money, providing care, socialising) depending on the research questions addressed. The goal of name generators is to generate a list of names; i.e., to elicit reference persons who are part of the ego's personal network. The choice, number, and wording of the name generator items need to be carefully considered, because they strongly influence participants' responses (e.g., Marin and Hampton 2007). Likewise, network measures such as size, density, or composition (e.g., proportion of kin) are often greatly affected by how names are generated. In step 2, respondents answer 'name interpreter' questions by providing information on the alters (alter attributes) and the relationships between ego and the alters (ego-alter ties). For example, respondents can be asked about the age, gender, or place of residence of the mentioned alters, and about the duration or quality of the relationship with the alters (e.g., frequency of contact or degree of emotional closeness). In step 3, using a so-called 'alter-alter matrix' (or 'name-interrelaters'), the respondent is asked to qualify the relationships between the alters. While this step is not always applied in studies on ego-centric networks, it is necessary if the researchers want to examine the structure of the network, such as its density or reciprocity (ratio of ties that are mutual). As we mentioned above, in family-related research, an alternative method of inter- 
rogating ego-alter and alter-alter relationships (steps 2 and 3) has been developed, which is based on the CSS method from socio-centric networks (Widmer 1999). First, using a name generator, respondents (egos) are prompted to give a list of people (alters). Second, for all relationships - i.e., for all ego-alter relationships and all potential alter-alter relationships respondents are asked about the type or quality of the relationships (e.g., the level of support or the degree of emotional closeness they provide). The requirements for the survey questionnaire therefore increase, as a 'complete' matrix is generated for all relationships.

In the 2013 MosaiCH-ISSP survey, the following name generator was used: 'Who are the people you currently consider as important family members? By important family members, we mean the people who have played a role, either positive (these people helped or supported you) or negative (they annoyed you), over the past 12 months, and who you consider as being part of your family'. In the questionnaire, up to 11 alters could be named. Next, using name interpreters, the respondents were asked about these alters (e.g., age, gender) and the relationships they had with them, including the length of time they have known the alters, and the relationship status between the ego and the alter (e.g., child, partner). In the third step, respondents were asked which alters provided them with emotional support, with material support, influenced them, and annoyed them. They were also asked to provide the same information for all the alters mentioned. This was done by following the CSS approach and eliciting binary responses (yes/no). For measuring material support, the following items were used: (1) 'Among the family members you listed, who do you think would provide you material support or give you a helping hand when you are facing difficulties, such as financial shortfalls, child care, shopping, transport, housework?' ; and (2) 'Among the family members you listed (including yourself), who do you think, would provide material support to first person named or give her/him a helping hand when she/he is facing difficulties, such as financial shortfalls, child care, shopping, transport, housework, etc.?' and similarly for the second, third, etc. person named. These responses provided information on alter-to-ego support (1) and ego-to-alter and alter-to-alter support (2).

\subsection{Levels and Methods of Analysis}

A key advantage of the network approach is its ability to analyse families at different (and interrelated) levels of analysis: actor, dyads, and network. Thus, researchers should first clarify whether the study aims to focus at the level of individuals, ego-alter relationships (so-called alter or tie level of analysis), networks (so-called network level of analysis), or multiple levels. At the individual level, for example, researchers can test whether large and cohesive family networks increase individuals' well-being or are, conversely, burdensome because of the demands involved in sustaining them. At the alter level, network analysts can address research questions such as the following: Are family members using internet-based communication to stay in contact with relatives? Does the interaction frequency influence whether a relationship is supportive? Network-level analysis can be divided into so-called compositional and structural measurements. Among the questions that may be asked at the network level are: 'What is the proportion of alters who live outside the household?' (composition); and 'What is the percentage of people in the family network who support each other?' (structure). A question at multiple levels of analysis could be whether gender (at the individual or dyadic level) impacts support provision within the network. In the 2013 MosaiCH-ISSP data, 666 respondents reported a total of 4140 relationships, with a mean network size of 
$7.2(\mathrm{SD}=3.0 ; \min =2 ; \max =12) .{ }^{4}$ An important alter-level feature is the status of relationships; meaning the role of the ego-alter relationship. Table 8.1 shows the distribution of the relationship status in eight categories. ${ }^{5}$

\section{Table $8.1 \quad$ Distribution of relationship status (alter level, $N=4140$ )}

\begin{tabular}{lcc}
\hline & $\mathbf{N}$ & $\mathbf{\%}$ \\
\hline Child & 855 & 20.6 \\
Partner & 510 & 12.3 \\
Father/mother & 584 & 14.1 \\
Brother/sister & 667 & 16.1 \\
Extended family & 750 & 18.1 \\
In-law & 532 & 12.0 \\
Friend & 254 & 6.1 \\
Other & 24 & 0.6 \\
Total & 4140 & 100 \\
\hline
\end{tabular}

We can see that 20.6 per cent of the individuals identified as important family members (alters) were children, 18.1 per cent were extended family members (e.g., grandparents, aunts, uncles, cousins, siblings' partners, or stepfamily members), and 16.1 per cent were siblings. We can further observe that 12.3 per cent of the important family network members named were partners, 14.1 per cent were fathers or mothers, 12.0 per cent were in-laws (parents-in-law, siblings-in-law, or children-in-law), and about 6 per cent were friends.

Staying on the alter-level description and turning our attention to the question of social support, we found that respondents reported receiving material support from 75.6 per cent of the alters. In other words, three-quarters of the named family members were perceived as sources of support when the respondent needed help with, for example, a financial shortfall, child care, shopping, transport, or housework.

SNA can also provide a network-level description of the network that has compositional and structural dimensions. At this level, we can analyse the networks as cases, and thus have the same number of cases as egos. One of the main features of a network is its density. Density is measured as the ratio of existing ties to all possible ties in a network, and ranges from zero (no existing ties) to one (all possible ties exist). There is considerable evidence suggesting that densely connected family networks are beneficial in different life situations. Because densely-knit networks and direct relationships generate mutual support, trust and obligations, effective norms, and information flow, network members can better coordinate their efforts to help others, including in times of need and hardship (Coleman 1988; Milardo 1988; Wellman and Frank 2001). Thus, having dense networks can promote bounded solidarity, the adoption of an exclusive identity, and a strong sense of belonging. However, sparser networks have been shown to provide advantages in other life circumstances. Less dense networks allow for more individual autonomy, the creation of broader identities, the exchange of non-redundant information, and less normative control (Burt 2009; Granovetter 1973; Lin et al. 2001), which can, in turn, facilitate instrumental action (e.g., finding a job), and make it easier for individuals to adapt to new or non-normative situations, such as divorce or coming out as homosexual (Gerstel et al. 1985; Waldner and Magrader 1999). In our illustration using data from the 2013 MosaiCH-ISSP survey, we decided to calculate the density based on the four kinds of relationships measured: emotional support, material support, influence, and annoyance; while 
excluding ego-alter relationships. ${ }^{6}$ The mean density of the 666 networks was found to be 0.41 $(\mathrm{SD}=0.22 ; \min =0 ; \max =1)$.

As well as performing descriptive analysis, SNA uses graphical representations of networks to uncover the structural patterns of relationships. These network diagrams (also called graphs or sociograms) can help researchers examine the network's layout, clusters of interest, and the positions of the actors (i.e., whether they play central or key roles, such as that of brokers). Network mapping can also help family practitioners identify issues and diagnose impacts. In qualitative SNA, network maps are often used as tools during interviews for visualising research participants' relationships and elicit information on their networks (e.g., underlying stories and meanings).

Figure 8.1 shows the family network of a respondent of the 2013 MosaiCH-ISSP survey. This ego was a divorced woman who was aged 42 at the time of the interview, and who was living with her two sons in a little town in the French-speaking part of Switzerland. She mentioned eight alters as important family members: her two sons and their father (her ex-partner), her mother, her brother and his partner, and two female friends. The direction of the arrow in the graph indicates who is providing emotional support to whom from the perspective of ego. The (arbitrary) position of the nodes on the graph was determined by a network layout algorithm based on node connectivity and aesthetic criteria.

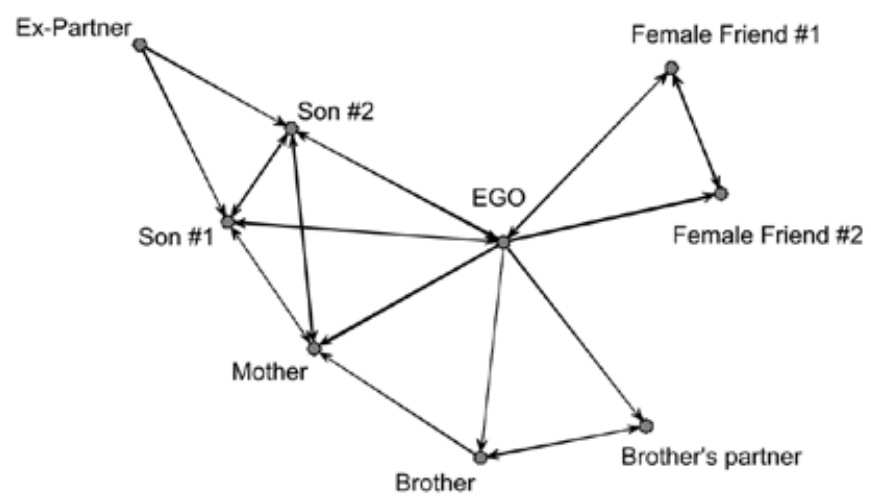

Source: Own representation.

\section{Figure 8.1 Family network}

In addition to the descriptive analysis and visualisations used to portray relationships and structures in family networks, different modes of multivariable analysis can be applied to the network data. However, we should first emphasise the need for a distinction between exploratory (structure-reducing) methods and structure-testing approaches, which include a network feature as an independent or a dependent variable in the statistical model.

Exploratory approaches, such as cluster-analytical approaches, have been widely used in family research to determine the diversity of network patterns. The clusters represent common types of family configurations that are formed by systematically grouping together similar networks based on size, connectivity, spatial dispersion, proportion of kin versus non-kin, etc. For example, using the Family Survey of the German Youth Institute and drawing on Wellman's 
(1979) concept of the lost, saved, and liberated community, Diaz-Bone (1997) identified three types of families: 'disintegrated', 'familial integrated', and 'modern' (see also Hennig 2007 for a more recent study using a similar approach). Exploratory approaches on the alter level can be used to show how the status of a relationship (and the respective social role) matches specific types of support (Chua 2013).

In a structure-testing/modelling approach, both alter-level and network-level information can be included in regression analysis. Analytically, whether network characteristics are 'antecedents or consequences' (Borgatti and Foster 2003), and are thus independent or dependent variables in the analysis, must be determined. The use of network-level information (e.g., size, density, or composition) is particularly common in family research, as it allows researchers to study differences in family structures. For instance, an important strand of research has examined how different types of social networks affect people's health and well-being (e.g., Agneessens et al. 2006; Fiori et al. 2006; Litwin 2010; Litwin and Stoeckel 2014; Perry and Pescosolido 2012; Sapin et al. 2016).

\subsection{Family Networks as Multilevel Structures: An Example}

In this section, we present multilevel models (MLM) as an approach to study ego-centric networks. Family networks can be specified with a two-level model consisting of family relationships (level 1) nested within ego-centric networks (level 2). The aim of this approach is to examine to what extent the presence or values of family relationships between egos (respondents) and their family members vary by the characteristics of the egos, their family members, their family ties, and the structure or composition of their family networks.

While hierarchical MLM are widely applied to nested data structures, and were pioneered for ego-centric networks in the late 1990s (for more details, see de Miguel Luken and Tranmer 2010; Snijders and Bosker 2003; Snijders et al. 1995; van Duijn et al. 1999; Wellman and Frank 2001), their use in family studies remains limited. More commonly, either an alter-level analysis (e.g., analysis of specific relationships, typically between ego and parents or ego and children) or a network-level analysis (e.g., analysis of family structures as causes or consequences of human behaviours) is used separately.

The major advantage of MLM is that these models can simultaneously account for alter-level and network-level variation (Vacca 2018). The idea behind this approach is that the 'function' of particular ego-alter dyads can be explained by properties of ego-alter relationships and the structure of the network, as well as by ego attributes. MLM adjust standard errors for the clustering of alters and ties in ego-centric networks, which violates the assumption of independence of observations. In particular, MLM allow researchers to avoid the aggregation of alter-level measures into network-level indices, which may be associated with a loss of information about variation in alter-level responses within networks. MLM can also assess the effects of the network structure and composition, net of the effects of single dyads. A further advantage of MLM is that these models can be specified to allow alter-level parameters to vary across egos or ego-centric networks, and to test cross-level interactions between alter and ego-level variables (e.g., ego-alter homophily). This feature is particularly interesting for family researchers who want to examine family dyads in the context of wider network structures of personal networks.

In the MosaiCH-ISSP data, 4140 alters/ego-alter relationships (level 1) are clustered within the higher-level units of 666 ego-centric networks (level 2). To address the research question 
of whether the relational and structural properties of family networks and the characteristics of the egos affect the provision of material support, we used multilevel regression analysis. Because the dependent variable is binary coded, binary logistic regression models are applied in which the unit of analysis is the alter-to-ego relationship, and the dependent variable is whether a given alter provides material support to ego. In each model, the relative chance of an alter-to-ego tie providing support as opposed to not providing support is assessed. Positive coefficients indicate higher probabilities of the provision of material support compared with the reference category; negative coefficients indicate that an alter is less likely to provide material support.

The results of regression models are shown in Table 8.2. Owing to missing values, our analytical sample is reduced to 612 egos/networks and 3912 alters with the inclusion of network density. Model 0 is the empty model with intercept only. Compared with the fit of a single alter-level null binary logistic model (not shown here), Model 0 is a significant improvement (log-likelihood ratio test: $p<0.001$ ). In other words, before controlling for covariates, the chance of receiving material support varies significantly from ego to ego, and a multilevel approach is relevant to account for the clustering of alters by ego-centric networks. In Model 1, the relationship status (in eight categories) is added as an alter-level covariate. In Model 2, only ego's gender and age (in four categories) and the network density are included as network-level covariates. Model 3 includes all of the variables included in Models 1 and 2. The results of Model 1 show that ego's partner and parents are more likely to be perceived as providing material support than his/her children, with children set as the reference category. Conversely, members of the extended family are perceived as being less supportive than children. Model 2 shows that respondents aged 18-30 are more likely than respondents aged 31-50 to report that they are being supported by their alters. Respondents are also more likely to perceive that they are being supported by an alter as the density of the networks increased; i.e., as alters are interacting more. The inclusion of both alter-level and network-level characteristics in Model 3 provides a better fit than the previous models, as the reduction of AIC and BIC indices indicates. This model shows that the effect of density remains significant when controlling for relationship status, and vice versa. The provision of material support within families varies both with the status of the relationships and the network density, and both effects are significant. While the relationship status and the respondents' characteristics are key predictors of receiving support, the network approach shows that denser networks facilitate the supportive behaviour of ties and individuals. Family members and family ties are more likely to provide material support in denser networks. The characteristics of both individuals and relationships, and the structure of networks affect the provision of support. When social support studies treat each relationship as a discrete dyad, they thus ignore the structure of the network that may facilitate or impede the supportive behaviour of ties. Likewise, an analysis that focuses solely on the respondent or the network level neglects variation in the kinds of relationships that provide support. The multilevel network analysis allows researchers to take into consideration the interplay between individual characteristics, relational patterns, and network facilitation. 
Table 8.2 Results of multilevel logistic regression. Beta coefficients and standard errors (in brackets). Dependent variable: Alter-to-ego material support (1: support given, 0: no support given)

\begin{tabular}{|c|c|c|c|c|c|c|c|}
\hline \multirow[b]{2}{*}{ Intercept } & Model 0 & \multicolumn{2}{|c|}{ Model 1} & \multicolumn{2}{|c|}{ Model 2} & \multicolumn{2}{|c|}{ Model 3} \\
\hline & $1.68^{* * * *}(0.09)$ & $1.77^{* * *}$ & $(0.14)$ & $-0.68^{* * * *}$ & $(0.20)$ & $-1.04^{* * * *}$ & $(0.26)$ \\
\hline \multicolumn{8}{|l|}{ Alter-level variables } \\
\hline \multicolumn{8}{|l|}{ Child (ref.) } \\
\hline Partner & & $2.04^{* * *}$ & $(0.23)$ & & & $2.23^{* * * *}$ & $(0.25)$ \\
\hline Father/mother & & $1.21^{* * *}$ & $(0.20)$ & & & $1.20^{* * * *}$ & $(0.20)$ \\
\hline Brother/sister & & -0.12 & $(0.16)$ & & & 0.00 & $(0.16)$ \\
\hline Extended family & & $-1.36^{* * *}$ & $(0.15)$ & & & $-1.22^{* * * *}$ & $(0.15)$ \\
\hline In-law & & -0.13 & $(0.16)$ & & & 0.01 & $(0.17)$ \\
\hline Friend & & -0.07 & $(0.23)$ & & & 0.26 & $(0.23)$ \\
\hline Other & & -0.78 & $(0.60)$ & & & -0.12 & $(0.63)$ \\
\hline \multicolumn{8}{|l|}{ Network-level variables } \\
\hline Ego female & & & & 0.10 & $(0.13)$ & 0.14 & $(0.15)$ \\
\hline Ego age: $18-30$ & & & & $0.40^{*}$ & $(0.19)$ & $0.59^{* *}$ & $(0.22)$ \\
\hline \multicolumn{8}{|l|}{ Ego age: $31-50$ (ref.) } \\
\hline Ego age: $51-65$ & & & & 0.29 & $(0.17)$ & $0.52^{* *}$ & $(0.19)$ \\
\hline Ego age: $66-100$ & & & & -0.04 & $(0.19)$ & 0.30 & $(0.22)$ \\
\hline Network density (alter-alter ties) & & & & $5.61^{* * *}$ & $(0.41)$ & $6.17^{7 * * *}$ & $(0.48)$ \\
\hline AIC & 4203.37 & 3827.64 & & 3710.59 & & 3376.09 & \\
\hline BIC & 4216.03 & 3884.59 & & 3754.49 & & 3463.90 & \\
\hline Log likelihood & -2099.68 & -1904.82 & & -1848.30 & & -1674.05 & \\
\hline Number observations & 4,140 & 4,140 & & 3,912 & & 3,912 & \\
\hline Number groups & 666 & 666 & & 612 & & 612 & \\
\hline Intercept & 2.15 & 2.89 & & 1.06 & & 1.53 & \\
\hline
\end{tabular}

Note: $* * * p<0.001, * * p<0.01, * p<0.05$.

\section{CONCLUSION AND OUTLOOK: POTENTIALS AND PITFALLS OF THE NETWORK APPROACH AND RESEARCH AGENDA FOR THE STUDY OF FAMILIES}

By its focus on relationships, the network approach has considerable potential in family research. By directing our attention to the connections and their structural patterns, rather than to the characteristics of particular individuals, the network approach offers an alternative way to conceptualise families. It represents a holistic and relational conception of families that can enable academics, practitioners, and clinicians with a wide array of interests in the field to uncover actual - as opposed to assumed - family relationship patterns. This can, in turn, encourage the recognition of a plurality of family forms. It is likely that in societies characterised by globalisation and individualisation processes, studying the networked patterns of family life across time and place will continue to appeal to family scholars. Family research can look back to a long tradition of network studies, such as the so-called 'Familiensurvey' of the German Youth Institute (Bertram 1991), or, more recently, the analysis on family networks from the German Family Panel pairfam project (e.g., Lois 2016, but see Brüderl et al. 2013 for interviewer bias in network data collection in pairfam). 
Although the network approach offers some clear advantages, it also has potential pitfalls. First, the family and intimate relationships under investigation are only a subset of all of the social relationships within which individuals are embedded. It is, therefore, essential that researchers are explicit in their conceptualisation and operationalisation of network constructs that should be informed and justified by substantive theory. In particular, justifying the establishment of the network boundaries and the measurement of the relationships being studied are fundamental issues that must be addressed when conducting social network research (Laumann et al. 1983). There is a clear need for the development of standardised network measurement procedures, which could facilitate comparisons across studies and replicability. A second challenge in network-based research is that data collection is time-consuming and costly. This issue has become even more pressing because of the complementary strengths to combine contextual information on relationships and networks with network data for effective network analysis. This difficulty may partly explain why there are far fewer panel family surveys that include ego-centric network modules than, for example, national household panel surveys. This gap should encourage family researchers to use innovative data collection strategies, including digital and social media, given that family interactions are increasingly mediated through digital technologies. A third challenge in social network research is ethical dilemmas. The risks associated with asking participants to identify people based on their social relationships require careful consideration in order to protect participants (e.g., Kadushin 2005), and may lead to restrictions on the use of network designs with multiple informants in family settings.

We conclude this chapter by suggesting some directions for future network-based family research. First, while not all network concepts have been widely used in family research, we believe that some concepts, such as multiplexity or transitivity (the "friends of my friends are my own friends' principle), could be particularly valuable to family studies. For example, these concepts may be used to further examine family balance and ambivalence in family relationships (de Bel et al. 2019; Girardin et al. 2018; Widmer and Lüscher 2011). Second, as we highlighted above, the network approach to families mostly uses an ego-centric perspective, while socio-centric approaches are rather scarce. This is surprising, as the development of network methods for socio-centric approaches is very advanced (e.g., Exponential Random Graph Models or Stochastic Actor-Oriented Models, such as SIENA). Thus, the potential for modelling network dynamics in the analysis of family networks is considerable. Even with its rather descriptive and exploratory methods, like its relational (community detection analysis, cluster analysis) or positional (structural equivalence) approaches to socio-centric analysis, SNA offers researchers many avenues for studying family networks. Following the example of Kennedy et al. (2015), developing network designs by including interviews with multiple family members could enable researchers to compare personal networks across family members, and to relate their overlaps/discrepancies to problems of interest to family studies (see, for example, Kalmijn 2003 about the impact of friendship network overlap on couple stability). Third, despite a scarcity of relevant longitudinal data, family researchers could take advantage of a recent trend in network research to examine how major life events are related to changes in family and intimate relationships. Finally, another promising avenue is to study how family relationships and family networks vary with other social contexts, such as the area or country in which individuals live using MLM to examine the effects of welfare states or family policies, for example. 


\section{NOTES}

1. Whether the network approach constitutes a conceptual framework or merely a set of methodological techniques is a matter of debate among network scholars (see e.g., Mische 2011). While there is no single formal statement of the network approach, there are some basic theoretical presuppositions and core ideas, which provide underlying intellectual unity of what we define here as 'the' network approach.

2. For exceptions, see Kennedy et al. (2015) for an innovative method on combined social networks of couples (so-called duocentric networks) where network data are collected from both partners; or Widmer and La Farga (2000) about a network design including interviews with all the significant family members (alters) of a certain person (ego) on all relationships within the family group, followed by interviews with any person who was cited by at least two alters, using a snowball-sampling technique.

3. For more information about the survey, see https://forscenter.ch/projects/mosaich/.

4. This calculation includes ego (the respondent) as part of the network. MosaiCH-ISSP data include a sample of 754 respondents. Among them, 12 respondents did not mention any alter and 76 respondents did not answer the questions about material support.

5. In the questionnaire, the variable had 16 categories and an 'other' category. The recoding into eight categories can be debated. Researchers need to adjust this categorisation according to their research interests.

6. An alternative option would be to calculate the density separately for each kind of tie. For example with material support, a tie from A to B is existing when A provides material support to B. Instead, we assigned tie values ranging from 0 to 4 with 4 indicating that all kinds of ties were existing. Network density was calculated by dividing the sum of tie values by the total number of ties times 4. Ego-alter ties were excluded from calculating the network density, because the density was included as predictor of ego-alter ties in regression models.

\section{REFERENCES}

Acock, A.C. and J.S. Hurlbert (1990), 'Social network analysis: A structural perspective for family studies', Journal of Social and Personal Relationships, 7 (2), 245-64. doi:10.1177/0265407590072006.

Agneessens, F., H. Waege, and J. Lievens (2006), 'Diversity in social support by role relations: A typology', Social Networks, 28 (4), 427-41. doi:10.1016/j.socnet.2005.10.001.

Antonucci, T.C., K.S. Birditt, C.W. Sherman, and S. Trinh (2011), 'Stability and change in the intergenerational family: A convoy approach', Ageing and Society, 31 (7), 1084-106. doi:10.1017/ S0144686X1000098X.

Bellotti, E. (2014), Qualitative Networks: Mixed Methods in Sociological Research, London: Routledge.

Bernard, H.R., P.D. Killworth, and L. Sailer (1979), 'Informant accuracy in social network data IV: A comparison of clique-level structure in behavioral and cognitive network data', Social Networks, 2 (3), 191-218. doi:10.1016/0378-8733(79)90014-5.

Bernardi, L. (2011), 'A mixed-methods social networks study design for research on transnational families', Journal of Marriage and Family, 73 (4), 788-803. doi:10.1111/j.1741-3737.2011.00845.x.

Bertram, H. (ed.) (1991), Die Familie in Westdeutschland: Stabilität und Wandel familialer Lebensformen, Opladen: Leske + Budrich.

Bidart, C. and D. Lavenu (2005), 'Evolutions of personal networks and life events', Social Networks, 27 (4), 359-76. doi:10.1016/j.socnet.2004.11.003.

Borgatti, S.P. and P.C. Foster (2003), 'The network paradigm in organizational research: A review and typology', Journal of Management, 29 (6), 991-1013. doi:10.1016/S0149-2063_03_00087-4.

Bost, K.K., M.J. Cox, M.R. Burchinal, and C. Payne (2002), 'Structural and supportive changes in couples' family and friendship networks across the transition to parenthood', Journal of Marriage and Family, 64 (2), 517-31. doi:10.1111/j.1741-3737.2002.00517.x. 
Bott, E. (1957), Family and Social Network: Roles, Norms and External Relationships in Ordinary Urban Families, 2nd edition, London: Tavistock.

Brüderl, J., B. Huyer-May, and C. Schmiedeberg (2013), 'Interviewer behavior and the quality of social network data', in P. Winker, N. Menold, and R. Porst (eds), Survey Standardization and Interviewers' Deviations: Impact, Reasons, Detection and Prevention, Frankfurt am Main: Peter Lang, pp. 147-60.

Budgeon, S. and S. Roseneil (2004), 'Editors' introduction: Beyond the conventional family', Current Sociology, 52 (2), 127-34. doi:10.1177/0011392104041797.

Burt, R.S. (2009), Structural Holes: The Social Structure of Competition, Boston, MA: Harvard University Press.

Chua, V. (2013), 'Contextualizing "networked individualism": The interplay of social categories, role relationships and tasks', Current Sociology, 61 (5-6), 602-25. doi:10.1177/0011392113489041.

Cicirelli, V. (2013), Sibling Relationships across the Life Span, New York: Springer Science and Business Media.

Coleman, J.S. (1988), 'Social capital in the creation of human capital', American Journal of Sociology, 94, 95-120. doi:10.1086/228943.

Crossley, N. (2010), 'The social world of the network. Combining qualitative and quantitative elements in social network analysis', Sociologica, 1, 1-34. doi:10.2383/32049.

de Bel, V., M. Kalmijn, and M.A.J. van Duijn (2019), 'Balance in family triads: How intergenerational relationships affect the adult sibling relationship', Journal of Family Issues, 40 (18), 2707-27. doi:10 $.1177 / 0192513$ X19860181.

de Miguel Luken, V. and M. Tranmer (2010), 'Personal support networks of immigrants to Spain: A multilevel analysis', Social Networks, 32 (4), 253-62. doi:10.1016/j.socnet.2010.03.002.

Diaz-Bone, R. (1997), Ego-zentrierte Netzwerkanalyse und familiale Beziehungssysteme, Wiesbaden: DUV.

Emirbayer, M. and J. Goodwin (1994), 'Network analysis, culture, and the problem of agency', American Journal of Sociology, 99 (6), 1411-54. doi:10.1086/230450.

Emirbayer, M. and A. Mische (1998), 'What is agency?', American Journal of Sociology, 103 (4), 962-1023. doi:10.1086/231294.

Felmlee, D.H. (2001), 'No couple is an island: A social network perspective on dyadic stability', Social Forces, 79 (4), 1259-87. doi:10.1353/sof.2001.0039.

Finch, J. (2007), 'Displaying families', Sociology, 41 (1), 65-81. doi:10.1177/0038038507072284.

Fiori, K.L., T.C. Antonucci, and K.S. Cortina (2006), 'Social network typologies and mental health among older adults', The Journals of Gerontology, Series B, 61 (1), 25-32. doi:10.1093/geronb/61.1.P25.

Gerstel, N., C.K. Riessman, and S. Rosenfield (1985), 'Explaining the symptomatology of separated and divorced women and men: The role of material conditions and social networks', Social Forces, 64 (1), 84-101. doi:10.1093/sf/64.1.84.

Girardin, M., E.D. Widmer, I.A. Connidis, A.M. Castrén, R. Gouveia, and B. Masotti (2018), 'Ambivalence in later-life family networks: Beyond intergenerational dyads', Journal of Marriage and Family, 80 (3), 768-84. doi:10.1111/jomf.12469.

Giudici, F. and E. Widmer (2017), 'Gendered occupational shifts in the transition to parenthood: The influence of personal networks', Sociology, 51 (2), 429-49. doi:10.1177/0038038515601857.

Granovetter, M.S. (1973), 'The strength of weak ties', American Journal of Sociology, 78 (6), 1360-80. doi:10.1086/225469.

Granovetter, M.S. (1985), 'Economic action and social structure: The problem of embeddedness', American Journal of Sociology, 91 (3), 481-510. doi:10.1086/228311.

Hein, K., M. Schier, and T. Schlinzig (2019), 'Social relations, space, and place: Reconstructing family networks in the context of multi-local living arrangements', in M. Halatcheva-Trapp, G. Montanari, and T. Schlinzig (eds), Family and Space: Rethinking Family Theory and Empirical Approaches, London: Routledge, pp. 73-87.

Hennig, M. (2007), 'Re-evaluating the community question from a German perspective', Social Networks, 29 (3), 375-90. doi:10.1016/j.socnet.2007.01.008.

Herz, A. (2012),'Erhebung und Analyse ego-zentrierter Netzwerke', in S. Kulin, K. Frank, D. Fickermann, and K. Schwippert (eds), Soziale Netzwerkanalyse Theorie, Methoden, Praxis, Münster: Waxmann, pp. 133-50. 
Herz, A. (2015), 'Relational constitution of social support in migrants: Transnational personal communities', Social Networks, 40, 64-74. doi:10.1016/j.socnet.2014.08.001.

Herz, A., L. Peters, and I. Truschkat (2015), 'How to do qualitative structural analysis: The qualitative interpretation of network maps and narrative interviews', Forum Qualitative Sozialforschung/Forum: Qualitative Social Research, 16 (1). doi:10.17169/fqs-16.1.2092.

Hollstein, B. (2011), 'Qualitative approaches', in J. Scott and P.J. Carrington (eds), The Sage Handbook of Social Network Analysis, Los Angeles: Sage, pp. 404-16.

Jamieson, L. (1998), Intimacy: Personal Relationships in Modern Societies, Cambridge: Polity Press.

Johnson, M.P. and L. Leslie (1982), 'Couple involvement and network structure: A test of the dyadic withdrawal hypothesis', Social Psychology Quarterly, 45 (1), 34-43. doi:10.2307/3033672.

Jones, A. (2018), 'Revisiting Bott to connect the dots: An exploration of the methodological origins of social network analysis', Forum Qualitative Sozialforschung/Forum: Qualitative Social Research, 19 (21). doi:10.17169/fqs-19.2.2905.

Kadushin, C. (2005), 'Who benefits from network analysis: Ethics of social network research', Social Networks, 27 (2), 139-53. doi:10.1016/j.socnet.2005.01.005.

Kalmijn, M. (2003), 'Shared friendship networks and the life course: An analysis of survey data on married and cohabiting couples', Social Networks, 25 (3), 231-49. doi:10.1016/S0378-8733( 03)00010-8.

Kennedy, D.P., G.L. Jackson, H.D. Green, T.N. Bradbury, and B.R. Karney (2015), 'The analysis of duocentric social networks: A primer', Journal of Marriage and Family, 77 (1), 295-311. doi:10 .1111 jomf.12151.

Krackhardt, D. (1987), 'Cognitive social structures', Social Networks, 9 (2), 109-34. doi:10.1016/ 0378-8733(87)90009-8.

Laumann, E., P.V. Marsden, and D. Presnky (1983), 'The boundary specification problem in network analysis', in R.S. Burt and M. Minor (eds), Applied Network Analysis: A Methodological Introduction, Beverley Hills, CA: Sage, pp. 18-34.

Lazega, E. and T.A. Snijders (eds) (2015), Multilevel Network Analysis for the Social Sciences: Theory, Methods and Applications, Vol. 12, New York: Springer.

Lenz, K. (2009), Soziologie der Zweierbeziehung. Eine Einführung, Wiesbaden: VS Verlag für Sozialwissenschaften.

Lenz, K. and F. Nestmann (2009), 'Persönliche Beziehungen - Eine Einleitung', in K. Lenz and F. Nestmann (eds), Handbuch persönliche Beziehungen, Weinheim und München: Juventa, pp. 9-25.

Lin, N., K.S. Cook, and R.S. Burt (2001), Social Capital: Theory and Research, New Brunswick, NJ: Transaction Publishers.

Litwin, H. (2010), 'Social networks and well-being: A comparison of older people in Mediterranean and non-Mediterranean countries', Journals of Gerontology Series B: Psychological Sciences and Social Sciences, 65 (5), 599-608. doi:10.1093/geronb/gbp104.

Litwin, H. and K.J. Stoeckel (2014), 'Confidant network types and well-being among older Europeans', The Gerontologist, 54 (5), 762-72. doi:10.1093/geront/gnt056.

Lois, D. (2016), 'Types of social networks and the transition to parenthood', Demographic Research, 34, 657-88. doi:10.4054/DemRes.2016.34.23.

Lubbers, M.J., J.L. Molina, J. Lerner, U. Brandes, J. Ávila, and C. McCarty (2010), 'Longitudinal analysis of personal networks: The case of Argentinean migrants in Spain', Social Networks, 32 (1), 91-104. doi:10.1016/j.socnet.2009.05.001.

Marin, A. and K.N. Hampton (2007), 'Simplifying the personal network name generator: Alternatives to traditional multiple and single name generators', Field Methods, 19 (2), 163-93. doi:10.1177/ 1525822 X06298588.

Marsden, P.V. (2011), 'Survey methods for network data', in J. Scott and P.J. Carrington (eds), The Sage Handbook of Social Network Analysis, Thousand Oaks, CA: Sage, pp. 370-88.

Milardo, R.M. (ed.) (1988), Families and Social Networks, Thousand Oaks, CA: Sage.

Mische, A. (2011), 'Relational sociology, culture, and agency', in J. Scott and P.J. Carrington (eds), The Sage Handbook of Social Network Analysis, London: Sage, pp. 80-97. 
Mitchell, J.C. (1969), Social Networks in Urban Situations: Analyses of Personal Relationships in Central African Towns, Manchester: Manchester University Press.

Molina, J.L., S. Petermann, and A. Herz (2015), 'Defining and measuring transnational social structures', Field Methods, 27 (3), 223-43. doi:10.1177/1525822X14556254.

Morgan, D. (2011), Rethinking Family Practices, Basingstoke: Springer.

Mueller, M.M., B. Wilhelm, and G.H. Elder, Jr. (2002), 'Variations in grandparenting', Research on Aging, 24 (3), 360-88. doi:10.1177/0164027502243004.

Pahl,R. and L. Spencer(2010), 'Family, friends, and personal communities: Changing models-in-the-mind', Journal of Family Theory and Review, 2 (3), 197-210. doi:10.1111/j.1756-2589.2010.00053.x.

Perry, B.L. and B.A. Pescosolido (2012), 'Social network dynamics and biographical disruption: The case of "first-timers" with mental illness', American Journal of Sociology, 118 (1), 134-75. doi:10 $.1086 / 666377$.

Prell, C. (2012), Social Network Analysis: History, Theory and Methodology, London: Sage.

Ryan, L. (2011), 'Migrants' social networks and weak ties: Accessing resources and constructing relationships post-migration', The Sociological Review, 59 (4), 707-24. doi:10.1111/j.1467-954X.2011 .02030.x.

Sapin, M., E.D. Widmer, and K. Iglesias (2016), 'From support to overload: Patterns of positive and negative family relationships of adults with mental illness over time', Social Networks, 47, 59-72. doi:10.1016/j.socnet.2016.04.002.

Scott, J. (2017), Social Network Analysis, 4th edition, London: Sage.

Silverstein, M. and A. Marenco (2001), 'How Americans enact the grandparent role across the family life course', Journal of Family Issues, 22 (4), 493-522. doi:10.1177/019251301022004006.

Smart, C. (2007), Personal Life, Cambridge: Polity Press.

Snijders, T.A.B. and R.J. Bosker (2003), Multilevel Analysis: An Introduction to Basic and Advanced Multilevel Modelling, London: Sage.

Snijders, T.A.B., M. Spreen, and R. Zwaagstra (1995), 'The use of multilevel modeling for analysing personal networks: Networks of cocaine users in an urban area', Journal of Quantitative Anthropology, 5, 85-105.

Vacca, R. (2018), 'Multilevel models for personal networks: Methods and applications', Statistica Applicata, Italian Journal of Applied Statistics, 30 (1), 59-97. doi:10.26398/IJAS.0030-003.

van Duijn, M.A.J., J.T. van Busschbach, and T.A.B. Snijders (1999), 'Multilevel analysis of personal networks as dependent variables', Social Networks, 21 (2), 187-210. doi:10.1016/S0378-8733(99)00009-X.

Viry, G. (2012), 'Residential mobility and the spatial dispersion of personal networks: Effects on social support', Social Networks, 34 (1), 59-72. doi:10.1016/j.socnet.2011.07.003.

Viry, G., O. Ganjour, J.A. Gauthier, E. Ravalet, and E. Widmer (2017), 'Analysing the role of social visits on migrants' social capital: A personal network approach', Social Inclusion, 5 (4), 209-25. doi: $10.17645 /$ si.v5i4.1164.

Voorpostel, M. (2013), 'Just like family: Fictive kin relationships in the Netherlands', The Journals of Gerontology Series B, 68 (5), 816-24. doi:10.1093/geronb/gbt048.

Waldner, L.K. and B. Magrader (1999), 'Coming out to parents: Perceptions of family relations, perceived resources, and identity expression as predictors of identity disclosure for gay and lesbian adolescents', Journal of Homosexuality, 37 (2), 83-100. doi:10.1300/J082v37n02_05.

Wellman, B. (1979), 'The community question: The intimate networks of east yorkers', American Journal of Sociology, 84 (5), 1201-31. doi:10.1086/226906.

Wellman, B. (1988), 'Structural analysis: From method and metaphor to theory and substance', in B. Wellman and S.D. Berkowitz (eds), Social Structures: A Network Approach, Vol. 2, Cambridge: Cambridge University Press, pp. 19-61.

Wellman, B. and K. Frank (2001), 'Network capital in a multilevel world: Getting support from personal communities', in N. Lin and K. Cook (eds), Social Capital: Theory and Research, Chicago, IL: Aldine de Gruyter, pp. 233-73.

Wellman, B. and S. Wortley (1989), 'Brothers' keepers: Situating kinship relations in broader networks of social support', Sociological Perspectives, 32 (3), 273-306. doi:10.2307/1389119. 
Wellman, B., P.J. Carrington, and A. Hall (1988), 'Networks as personal communities', in B. Wellman and S.D. Berkowitz (eds), Social Structures: A Network Approach, Vol. 2, Cambridge: Cambridge University Press, pp. 130-84.

Widmer, E.D. (1999), 'Family contexts as cognitive networks: A structural approach of family relationships', Personal Relationships, 6 (4), 487-503. doi:10.1111/j.1475-6811.1999.tb00205.x.

Widmer, E.D. (2016), Family Configurations: A Structural Approach to Family Diversity, Abingdon: Routledge.

Widmer, E.D. and L.-A. La Farga (2000), 'Family networks: A sociometric method to study relationships in families', Field Methods, 12 (2), 108-28. doi:10.1177/1525822X0001200202.

Widmer, E.D. and K. Lüscher (2011), 'Les relations intergénérationelles au prisme de l'ambivalence et des configurations familiales', Recherches Familiales, 1, 49-60. doi: 10.3917/rf.008.0049. 